\title{
The influence of globalisation and massification on public higher education in Malta: assessing the contextual realities
}

\author{
Borg, Colin
}

Department of Public Policy, University of Malta, Malta

\begin{abstract}
The main question that this paper seeks to explore is: What contextual factors and conditions are contributing to the present higher education environment in Malta?

To address this question, the author conducts a systematic study by examining the changing context of higher education from a legislative, economic and political perspective. The aim of this paper is to outline the determining influences that are shaping Malta's higher education context.

The research methods employed in this paper are mainly two: the first method involves the analysis of documents and data published in international academic journals and local reports. Statistics published by the National Commission for Further and Higher Education (NCFHE) and the National Statistics Office (NSO) were the main sources of local Maltese statistics. The second research method involves national and institutional data that was specifically requested by the author and that was never published before. NCFHE, the University of Malta (UM) and Malta College for Arts, Science and Technology (MCAST) were asked to provide data in order to present a comparative analysis by comparing local data with what has been published internationally. UM and MCAST are the two main public Maltese higher education institutions. In all instances headcount data is presented.
\end{abstract}

Keywords: Context, Massification, Globalisation, Performance. 


\section{Introduction: exploring two main contextual phenomena - massification and globalisation}

Higher Education Institutions (HEIs) across the globe, not least in Europe and Malta, are changing rapidly in an unprecedented manner. Massification and globalisation are two linked factors that led to a 'revolution' in the way institutions are governed and managed. Although 'revolution' seems an exaggeration, statistics show the extent of change that has happened in the last half of the twentieth century (Altbach, Reisberg \& Rumbley, 2009).

Globalisation was the first main contextual factor that led to a changing higher education scenario. International collaborations, students exchange programmes and the significant increase in the incoming full-time international students changed the student profile, especially when non-EU students hailing from many different cultures come to study in one of Malta's HEIs. These developments meant that higher education is no longer dominated by monopolistic structures but it is becoming increasingly competitive, both domestically and internationally. This phenomenon is mirrored in Malta's higher education governing system since public higher education institutions are no longer the sole players but are competing with private institutions that are enrolling an increasing number of students and have now become major players in this sector.

The second major contextual factor involves the significant increases of students that were experienced in Europe, North America and other parts of the world in the second half of the twentieth century. Zgaga, Teichler, Schuetze \& Wolter (2015) attribute the massification of higher education around the globe to two major causes: first, the economic development that resulted in an increasing demand for highly skilled and knowledgeable workforce. The first cause led to the second source of massification: that of having social mobility which essentially means that students coming from the working class started to register for higher education courses. Both causes were accentuated by the heavy investment and the political decisions of national governments that were intended to increase substantially the percentage of citizens attending higher education courses.

What has happened around the globe is reflected in Malta's experience in the last thirty years. In the final years of the 1980's the Maltese government's vision was of significantly increasing the number of students at tertiary level. Higher education has become accessible to a much higher percentage of the total Maltese population and this inevitably led to the massification of the University of Malta as the highest academic institution on the island and to the creation and eventual massification of MCAST, the main vocational higher education institution in Malta. Although higher education enrolment rates are still comparatively low, 26\% when compared to an average of $40 \%$ in the EU (NCHFE, 2016), it can be safely argued that higher education is no longer accessible only to the few intellectuals or well-off, high-status citizens. Malta's higher education became a way to 
move up the social ladder and to gain admission to a wide spectrum of professional careers. Consequently, the student population of Malta's higher education institutions is now socially and geographically diverse.

Both globalisation and massification significantly altered the manner in which institutions are governed and managed in various dimensions including: (i) the revisiting and the creation of new governing structures; (ii) more focus on managerial processes and active involvement of students and staff in management given the tough competition arising from a growing private sector; and (iii) stronger coordination with stakeholders.

The aim of this paper is to focus on the contributing factors towards a paradigm shift in the way that HEIs are governed and managed. Section 2 presents a statistical analysis of the growing private sector vis-à-vis the public sector from a Maltese national higher education perspective as well as the increasing use of online learning. Section 3 assesses the developing students` clientele from a massification perspective by presenting five main changing dimensions.

\section{The globalisation effect: erosion of state power and weakening of public HEIs' market share?}

The term 'globalisation' is becoming more frequently used than 'internationalisation': it not only represents the blurring of boundaries between nations but is also a direct reflection of worldwide economic developments. Furthermore, it embraces international higher education experiences that correspond to the erosion of the nation state's authority in determining higher education policies (Guri-Rosenblit, Sebkova \& Teichler, 2007). Around the world, changes in the context of higher education derived by globalisation led to a significant growth of private higher education institutions (Altbach, 2016).

The idea of having higher education exclusively offered by public institutions is now seriously challenged. In fact, Table 1 reveals that the number of private institutions more than doubled, from 31 to 73 , over the span of 5 years. It is important to note that this table excludes public self-accrediting institutions: MCAST, UM and the Institute for Tourism Studies (ITS) that are not required to apply for a license from NCHFE. The significant increase in private HEIs is a relatively recent development, since traditionally Malta's higher education has been predominantly provided through the University of Malta.

The increase in private HEIs is paralleled by the rise in the number of private sector students. Table 2 discloses an almost three-fold increase in the private sector market share in just five years, from 2010 until 2015. 
Table 1: Number of HEIs: public versus private

\begin{tabular}{|c|r|r|r|r|r|}
\hline Academic Year & $\mathbf{2 0 1}$ & $\mathbf{2 0 1 3}$ & $\mathbf{2 0 1 4} /$ & $\mathbf{2 0 1}$ & $\mathbf{2 0 1 6 /}$ \\
\hline Total number of licensed HE & & 64 & 59 & 71 & 80 \\
\hline Total private HEIs & 3 & 55 & 54 & 65 & 73 \\
\hline
\end{tabular}

Source: NCHFE (Data collected by the author)

Table 2: Share of Higher Education Students Population in terms of Private and Public Sector

\begin{tabular}{|r|r|r|r|r|r|r|}
\hline Year/Students & $\mathbf{2 0}$ & $\mathbf{2 0 1 1}$ & $\mathbf{2 0 1}$ & $\mathbf{2 0 1 3}$ & $\mathbf{2 0 1 4}$ & $\mathbf{2 0 1 5}$ \\
\hline Public Sector & 9,80 & 10,40 & 12,403 & 12,9 & 12,440 & 13,187 \\
\hline Private Secto & 92 & 1,30 & 2,315 & 3,69 & 2,598 & 2,833 \\
\hline Total & 10,7 & 11,71 & 14,718 & 16,67 & 15,038 & 16,020 \\
\hline
\end{tabular}

Source: NCHFE (2015)

This indicates that the private sector is growing rapidly and, consequently, the public sector is experiencing tough competition from private higher education organisations. In fact, while the ratio of students in public and private organisations was 11:1 in 2010, the gap decreased significantly in 2015 to a ratio of 5:1 (NCHFE, 2015: 27).

This development is consistent with what happened in the international arena where the growth of private higher education has been one of the most remarkable developments. In fact Sursock (2015) estimates that 30\% of today's global higher education is private. The change in the composition of Malta's student population has been accentuated by policy decisions adopted by the Maltese government. Legal notice 150 of 2015, which was introduced to inject greater internationalisation and pluralism into higher education, is a case in point. The Maltese government took a political decision to build a higher education niche with the aim of having a spill-over effect on the economy. As part of this national strategy, a new American University of Malta (AUM) and the Barts Medical School were brought to invest in Malta and Gozo respectively. The concern among many critics was that the new Legal Notice and the new policy direction of the Labour Government were indeed changing the parameters and foundations of higher education. This policy direction brought about fear of reducing the quality of Malta's higher education. The NCFHE explained that the main driving force behind the introduction of such changes was to give the possibility to Universities to obtain a licence even if they do not offer a wide range of programmes.

Globalisation also led HEIs to open branches overseas, to engage more in inter-institutional partnerships and business or community partnerships while receiving and sending a 
significant number of students on exchange programmes. Adroit use of information technology did help HEIs to catch the attention of new cohorts of students who could not be targeted before. HEIs are nowadays able to provide courses through e-learning or hybrid learning. The result was that distance learning courses have become more popular either by Universities developing a distance learning infrastructure or by setting up an entire eUniversity, as was the case in Estonia and Switzerland. In Iceland 17\% of the students undertook distance learning courses in 2009 (Beerkens-Soo \& Vossensteyn, 2009).

Table 3 shows that the number of online courses at UM is still very limited when considering that in Academic Year 2016/17 out of a total of 842 programmes only 40 were delivered online. In percentage terms this signifies a minimal figure of $5 \%$. A marginal percentage of $2 \%$ of all the study-units offered involve some form of online delivery when considering that out of a total of 5,000 study-units, only 102 units have an online method of teaching delivery.

Table 3: Number of Online Courses and Study-units delivered by UM and MCAST

\begin{tabular}{|l|l|l|l|}
\hline Academic Year & $\mathbf{2 0 0 7 / 8}$ & $\mathbf{2 0 1 2 / 3}$ & $\mathbf{2 0 1 6 / 7}$ \\
\hline Number of Online Courses - UM & 15 & 33 & 40 \\
\hline Number of Online Courses - MCAST & 0 & 0 & 0 \\
\hline Academic Year & $\mathbf{2 0 0 7 / 8}$ & $\mathbf{2 0 1 2 / 3}$ & $\mathbf{2 0 1 6 / 7}$ \\
\hline Number of Online Study-units - UM & 33 & 77 & 102 \\
\hline Number of Online Study-units - MCAST & 0 & 0 & 157 \\
\hline
\end{tabular}

Source: UM and MCAST (Data collected by the author)

Despite these low figures and percentages, the number of courses and study-units that include online teaching increased by almost three times in the span of ten years. Interestingly, although there are no online courses delivered at MCAST, the number of online study-units exceeds that of UM by a significant amount. This fact is surprising when considering the relatively high number of study-units offered by UM.

In summary, globalisation brought about tougher competition from the private sector, and stimulated further collaboration with international partners, while ICT facilitated the advent of online learning. Globalisation also contributed to the massification phenomenon that is reviewed in section 3 . 


\section{Massification: analysing student numbers and changes in the composition of the student body}

Five massification scenarios were identified in the course of this study. They influenced higher education governance and management either from a specific governmental policy direction or through the creation of new institutional structures, programmes, and initiatives as a response to the changing circumstances.

The first scenario involves the broadening of the Maltese HEIs' social base by providing free education and a stipend to all undergraduate students. This development can be explained either by the economic progress and societal developments that helped to shape today's modern societies or by multi-level policy actions steered by the EU and the national governments in order to increase the percentage of citizens who are studying and eventually graduate at higher education level. Europe's 2020 target strategy is a case in point. The main aim is to achieve a percentage figure of $40 \%$ of the population aged 30 to 34 who have completed tertiary or equivalent education. In 2013, Malta's share was relatively low, only $26 \%$, when compared to the EU's average of $36.9 \%$ (NCHFE \& MEDE, 2014) despite the Maltese government's policy of offering free tertiary education and stipends to all students. These favourable conditions are also accessible to repeating and mature students.

Across Europe, the EU's and national governments' efforts resulted in a significant increase in the student population in HEIs. In a study conducted by the European University Association (EUA), in 2015, among 451 higher education institutions, 62\% of the Universities experienced an increase in the number of students during the last five years (Cited in Sursock, 2015). In Malta, legislation compounded with societal changes led to a substantial increase in total student numbers. NCFHE analysed the number of students in higher education in the last twenty years (2015: 25). It was discovered that the student population at tertiary level increased from 6,362 in the year 2000 to 15,038 in 2014, a more than two-fold increase. In 2014 the University of Malta, as the country's main public HEI of the three islands (Malta, Gozo and Comino), had a share of $76 \%(11,476)$ of the total higher education student population (Malta Parliament, 2015). In 2017, the number of UM students remained at the same level and was significantly higher, six times as much, when compared to the figure of 1,928 MCAST students that were studying at MQF level 5 and upwards.

Policy decisions to abolish fees for higher education in 1974 and to provide stipends for all higher education students in 1979 meant that social groups that had never dreamt to make it to the higher education sphere were now attending tertiary level courses. The broadening of the social base was accentuated in 1987 when the Ministry responsible for education, in collaboration with the University of Malta, abolished the 'numerus clausus' system that was in force for a decade. Such a system meant that only students who were ranked in top 
positions through a points system were accepted for a University course. It was instead decided that students be accepted for almost all University courses if they are in possession of the necessary academic qualifications. MCAST was set up in order to encourage the upward trend in the number of higher education students between 1987 and 2000. This dedicated vocational college was also a response to Malta's decision to join the European Union and consequently to the globalisation forces. MCAST provides a route to higher education for those capable and highly-skilled students that are more oriented to vocational areas rather than academic domains.

Increasing women's participation in higher education represents the second factor, stemming from economic and societal developments that are a direct and an indirect result of both globalisation and government policy-making. While on one hand, globalisation had fuelled the idea of having a more active involvement of women in societal affairs and in the labour market, Malta's policy after EU membership in 2004, on the other hand, encouraged women to work rather than staying at home either through fiscal incentives or through practical initiatives such as free childcare. These policy decisions encouraged women to pursue careers and seek courses at tertiary level. A number of policy frameworks and strategies that include 'The Framework for Education Strategy for 2014 to 2024', 'The National Lifelong Learning Strategy 2020' and 'The Higher Education Strategy' highlighted the importance of reducing the gender gap and of having more active involvement of women in the labour market (NCHFE, 2016).

Societal changes and government decisions have therefore been crucial in attracting women as HEIs clients. The increase of women's participation in Malta's public higher education can be traced in Table 4. In the period 2008 to 2015 the percentage of women attending higher education courses when compared to the total public higher education students was $57 \%$, as an approximate average figure. Women's participation tallies with the female graduation rates that in 2015 achieved the mark of 56\% (NCHFE, 2016).

Table 4: Number of public higher education students in Malta by gender

\begin{tabular}{|l|l|l|l|l|l|l|l|}
\hline $\begin{array}{l}\text { Gender/ } \\
\text { Ac. Year }\end{array}$ & $\mathbf{2 0 0 8 / 9}$ & $\mathbf{2 0 0 9 / 1 0}$ & $\mathbf{2 0 1 0 / 1 1}$ & $\mathbf{2 0 1 1 / 1 2}$ & $\mathbf{2 0 1 2 / 1 3}$ & $\mathbf{2 0 1 3 / 1 4}$ & $\mathbf{2 0 1 4 / 1 5}$ \\
\hline Female & 5,536 & 5,685 & 6,073 & 6,900 & 7,350 & 6,888 & 7,276 \\
\hline Male & 4,080 & 4,124 & 4,332 & 5,350 & 5,744 & 5,552 & 5,664 \\
\hline Total & 9,616 & 9,809 & 10,405 & 12,250 & 13,094 & 12,440 & 12,940 \\
\hline
\end{tabular}

Source: NCHFE (Data collected by the author) 
This has been a global trend: Germany witnessed an increase of approximately $15 \%$ from 1975 to 2002 (Wolter, 2016) and a percentage of 58\% will be reached by the year 2025 . This is not an isolated case as the probability ratios of women participating in higher education courses are rising in all countries and in most countries the percentage figure will exceed $50 \%$ by the year 2025 . It is being projected that by that year countries such as Austria, United Kingdom and Iceland will achieve high percentage figures of $72 \%, 71 \%$ and $68 \%$ (Vincent-Lancrin, 2008).

The third factor consists of the growing number of international students from both EU and non-EU countries. The population of international students at the University of Malta is almost $10 \%$. This percentage figure compares well with countries such as the Czech Republic (10.5\%), Denmark (10.3\%) and the Netherlands $(10.2 \%)$ but is less than in Luxembourg (45.9\%), UK (18.5\%), Cyprus (17.5\%), Austria (15.9\%) and Belgium (11.2\%) (Eurostat, 2017). The increasing number of international students resulted in a threefold increase in the fees generated by the University of Malta. In Academic Year 2008-2009 the fees paid by EU and non-EU students totalled 1.5 million euros. The amount paid in Academic Year 2015/2016 increased to 5 million euros (Times of Malta, 2017). This meant more financial leverage for the University to invest in its infrastructure and programmes. The focus on international students especially on International Masters Programmes (IMPs) led to a dedicated organisation and a building situated at the Valletta Campus. Student mobility is not only measured in terms of regular students but also through other EU initiatives such as Erasmus programmes. Since 1987, Erasmus programmes has supported more than 3 million students to spend a few months in a foreign HEI. In Malta, the percentage student mobility through exchange programme is relatively low, only $2.5 \%$, when considering that the target of the Higher Education Area is of 20\% (NCHFE, 2016).

The fourth factor involves programmes or initiatives stemming from HEIs that are intended to cater for a segment of the population that never had the opportunity to study at tertiary level. Two examples could be cited from the University of Malta. The first involves the University's innovative programme of the Liberal Arts and Sciences introduced in Academic Year 2014/2015, which attracted a staggering figure of 797 students until Semester 1 of Academic Year 2016/2017. This programme is fundamentally different from all University courses since students can follow individual study-units instead a pre-set course of studies and it does not involve a time-limit if the registered students decide to continue their studies and obtain a certificate, diploma or even a degree. The second example comprises the UM's initiatives to target mature and part-time students. Mature students over 23 years of age can apply for almost any University course and can be potentially accepted following an interview by the Board of Faculty or Institute concerned.

The fifth factor is directly linked to the state-institutional initiatives to link programmes of study to today's industry-oriented professions since these career-oriented professions 
increase the chances of students becoming employable. Examples of academic areas that are heavily associated with the labour market and are an avenue to increase students demand to attend higher education courses are ICT, banking, finance, insurance, engineering and health-care. In six years, from academic year 2007/2008 to 2013/2014, an increase in student population of $39 \%$ was registered in social sciences, business and law; 50\% in Science; 27\% in Engineering, Manufacturing and Construction; 49\% in Health and Welfare and $70 \%$ in other essential services.

\section{Concluding remarks}

The development of a competitive global economy shaped national higher education systems in a manner that most scholars refer to as 'managed education'. This study is the first to investigate the domestic and global context influencing the trajectory of Malta's higher education system. The study sheds light on the fact that higher education is not only being influenced by the globalising effects but also by the decisions being taken domestically either by the government or by the HEI institutions themselves. The link between contextual change, governance and management requires further analysis in a separate paper. The increasing students` clientele is a contributing factor to multiplying structures and increasing staff within HEIs. This scenario could directly influence the wide array of performance indicators that are determined within institutions. The more complex the context, the more laborious are the structures and as a result it becomes more challenging to achieve the institutional and national performance targets.

\section{References}

Altbach, P. (2016) Global Perspectives on Higher Education, Johns Hopkins University Press.

Altbach, P., Reisberg, L., \& Rumbley L. (2009) Trends in Global Higher Education: Tracking an Academic Revolution, UNESCO.

Beerkens-Soo, M., \& Vossensteyn, H. (2009) Higher Education: Issues and Trends from an International Perspective, Centre for Higher Education Policy Studies.

Eurostat (2017) Learning Mobility Statistics - Statistics Explained. Retrieved from: http://ec.europa.eu/eurostat/statistics-explained/index.php/Learning_mobility statistics

Guri-Rosenblit, S., Sebkova, H., \& Teichler, U. (2007) Massification and Diversity of Higher Education Systems: Interplay of Complex Dimensions, Higher Education Policy, 20 (4), 373-389.

Malta Parliament (2015) Parliamentary Question 16556. Retrieved from: https://www.parlament.mt/en. 
NCHFE \& MEDE (2014) Higher Education Strategy for Malta, Malta's National Commission for Higher Education and Ministry for Education and Employment.

NCHFE (2015) Further and Higher Education Statistics 2013-2014, Malta's National Commission for Higher Education.

NCHFE (2016) Further and Higher Education Statistics 2014-2015, Malta's National Commission for Higher Education.

Sursock, A. (2015) Trends 2015: Learning and Teaching in European Universities, European University Association.

Times of Malta (2017) MCAST: An Investment in Malta's Future - Article written by Louis Galea - a former Education Minister. Retrieved from http://www.timesofmalta.com/articles/view/20030405/opinion/mcast-an-investment-inmaltas-future.152858.

Times of Malta (2017) Figures of foreign University students`fees shoot up. Retrieved from https://www.timesofmalta.com/articles/view/20170404/local/figure-of-foreignuniversity-students-fees-shoots-up.644414.

University of Malta, (2018, 11 January) Facts and Figures. Retrieved from http://www.um.edu.mt/about/uom/facts.

Vincent-Lancrin, S. (2008) The Reversal of Gender Inequalities in Higher Education: An On-going Trend, Higher Education to 2030, OECD, 10 (1), 265-298.

Wolter, A. (2016) Massification and Diversity: Has the Expansion of Higher Education Led to a Changing Composition of the Student Body? European and German Experiences, Humboldt-Universitätzu Berlin, Germany.

Zgaga, P., Teichler, U., Schuetze, H., \& Wolter, A. (eds.) (2015) Higher Education Reform: Looking Back - Looking Forward, Higher Education Research and Policy (HERP), Peter Lang Edition. 